\title{
Review
}

\section{Effects of cognitive behavioral therapy on orofacial pain conditions}

\author{
Noboru Noma ${ }^{1)}$, Yuki Watanabe ${ }^{2)}$, Akiko Shimada ${ }^{3)}$, Sho Usuda ${ }^{4)}$, Takashi Iida ${ }^{5)}$, Atsushi Shimada ${ }^{6}$, Yuto Tanaka ${ }^{7}$, \\ Yuka Oono ${ }^{8}$, and Keiichi Sasaki ${ }^{9}$ \\ ${ }^{1)}$ Department of Oral Diagnostic Sciences, Nihon University School of Dentistry, Tokyo, Japan \\ ${ }^{2}$ Division of Temporomandibular Disorders and Orofacial Pain, Department of Special Needs Dentistry, Showa University School of Dentistry, Tokyo, Japan \\ ${ }^{3)}$ Department of Geriatric Dentistry, Osaka Dental University, Osaka, Japan \\ 4) Department of Dentistry and Oral Surgery, Keio University School of Medicine, Tokyo, Japan \\ 5) Division of Oral Function and Rehabilitation, Department of Oral Health Science, Nihon University School of Dentistry at Matsudo, Matsudo, Japan \\ ${ }^{6}$ Division of Comprehensive Occlusal Function Recovery Clinic, Hospital of Kanagawa Dental University, Yokosuka, Japan \\ 7) Department of Special Care Dentistry, Osaka Dental University Hospital, Osaka, Japan \\ ${ }^{8)}$ Division of Dental Anesthesiology, Department of Diagnostic and Therapeutic Sciences, Meikai University School of Dentistry, Sakado, Japan \\ ${ }^{9}$ Division of Advanced Prosthetic Dentistry, Tohoku University Graduate School of Dentistry, Sendai, Japan
}

\begin{abstract}
Numerous studies have confirmed the effectiveness of cognitive behavioral therapy (CBT) for chronic pain, and it is generally regarded as an appropriate intervention. However, it may not be effective for some pain sites, and the duration of the effect may be limited. In addition, some studies of CBT lacked a comparison group. This review summarizes evidence for the effectiveness of CBT for orofacial pain and assists in the development of guidelines for orofacial pain management. A literature search in PubMed was performed for studies published from April 1990 through March 2020. The search keywords were "burning mouth syndrome," "temporomandibular disorders," "myofascial pain syndrome," "chronic orofacial pain conditions," "cognitive behavioral therapy," and "non-pharmacological therapy." The results indicate that CBT alone or in combination with other treatments, such as intraoral appliance, stress management, or biofeedback, is effective for the vast majority of orofacial pain cases. Therefore, dentists should consider using CBT to manage orofacial pain in their patients.
\end{abstract}

Keywords; burning mouth syndrome, cognitive behavioral therapy, myofascial pain syndrome, orofacial pain, temporomandibular disorders

\section{Introduction}

Patients reporting toothache often experience orofacial pain in the absence of a dental cause, which can result in unnecessary and ultimately ineffective dental treatments such as root canal treatment or tooth extraction [1]. Many patients are affected by continuous, unexplained pain after these dental treatments. Features of mental or personality disorders and even responses to everyday psychosocial factors can become somatized, causing patients to complain of "toothache." This is commonly seen in individuals with mental disorders such as somatic symptom disorder, schizophrenia, and major depressive disorder. Such patients are often referred to a psychiatrist or physician who recommends pharmacological therapy, including antidepressants or antipsychotic drugs.

An alternative method, cognitive behavioral therapy (CBT), can be effective for conditions such as chronic low back pain, primary headache, and irritable bowel syndrome [1-3]. The option of using noninvasive CBTlike approaches for chronic orofacial pain is desirable. Thus, a thorough examination and assessment after a CBT intervention is crucial in determining the effectiveness of treatments for orofacial pain. To investigate the effect of CBT on orofacial pain, a comprehensive literature review was conducted. Studies of patients with burning mouth syndrome (BMS), temporomandibular disorders (TMD), myofascial pain syndrome (MFP), and

Correspondence to Dr. Noboru Noma, Department of Oral Diagnostic Sciences, Nihon University School of Dentistry, 1-8-13 Kanda-Surugadai, Chiyoda-ku, Tokyo 101-8310, Japan

Fax: +81-3-3219-8346 E-mail: noma.noboru@nihon-u.ac.jp

J-STAGE Advance Publication: December 10, 2020

doi.org/10.2334/josnusd.20-0437

DN/JST.JSTAGE/josnusd/20-0437 other orofacial pain disorders that were treated by either CBT alone, other psychotherapies, pharmacological therapies, or combined therapies using intraoral appliances and physiotherapy were selected. The therapeutic outcomes analyzed were pain intensity, interference, pain relief satisfaction, and quality of life (QoL).

\section{Material and Methods}

This narrative review was conducted to determine whether CBT was more effective than control in reducing pain intensity and psychosocial problems in patients with orofacial pain. The orofacial pain conditions included BMS, TMD, MFP, and other orofacial pain disorders. The control groups included attention/placebo, usual treatment, no intervention, use of intraoral appliance, self-care management, and stress management with biofeedback, among other treatments (Tables 1-4). A literature search of PubMed was performed for studies published during the period from April 1990 through March 2020. The search string was "(burning mouth syndrome or temporomandibular disorders or myofascial pain syndrome or orofacial pain conditions) and (cognitive behavioral therapy or nonpharmacological therapy) and (1990/04/01:2020/03/31 [date-entry])".

\section{Results}

A total of 604 studies were retrieved by the PubMed query. Eighteen studies that were relevant to the question of this narrative review were selected. Of these 18 studies, three concerned BMS, seven concerned TMD, four concerned MFP, and four concerned other orofacial pain disorders. Tables 1-4 summarize the features of BMS, TMD, MFP, and other orofacial pain disorders and provide information on orofacial pain symptoms, interventions, controls, outcome variables, and main findings.

\section{Discussion}

BMS is an idiopathic condition involving recurrent burning or abnormal sensation in the mouth for more than $2 \mathrm{~h}$ per day for longer than 3 months. BMS is more common in postmenopausal women older than 50 years and is rare in women younger than 30 years. Overall prevalence is estimated to be between $0.7 \%$ and $15 \%$. Although BMS has been reported in men, it is much more prevalent in women. According to cochrane systematic reviews on BMS, CBT improved symptoms by focusing on cognitive restructuring [1-3]. Matsuoka et al. observed that cognitive factors such as pain-related catastrophizing and anxiety sensitivity affect pain severity and oral healthrelated QoL [4]. In addition to reprogramming these cognitive processes, interventions for habitual behaviors that aggravate and sustain symptoms may provide an even more effective treatment, such as CBT for orofacial pain. In fact, a CBT intervention for BMS patients dramatically improved pain intensity, pain catastrophizing, and oral health-related QoL. Bergdahl et al. reported that CBT alone reduced the pain intensity of BMS after 6 months [2], and Komiyama et al. reported that, in a small-group CBT intervention, patients had reduced anxiety index scores (state-trait anxiety inventory [STAI]) and lower pain intensity (numerical rating scale [NRS]) 
Table 1 Summary of characteristics of burning mouth syndrome

\begin{tabular}{|c|c|c|c|c|c|}
\hline Author (year) & OFP symptoms & Intervention & Control & Outcome variables & Main findings \\
\hline $\begin{array}{l}\text { Bergdahl et al. } \\
\text { (1995) }\end{array}$ & BMS & CT & APG & BMS intensity & $\begin{array}{l}\text { reduction of BMS intensity by cognitive } \\
\text { therapy in resistant BMS patients }\end{array}$ \\
\hline $\begin{array}{l}\text { Femiano et al. } \\
\text { (2004) }\end{array}$ & BMS & $\begin{array}{l}\text { cognitive psychotherapy } \\
\text { alone, combined psycho- } \\
\text { analysis and ALA }\end{array}$ & controls received placebo & VATS & $\begin{array}{l}\text { benefit of combined psychoanalysis and } \\
\text { ALA }\end{array}$ \\
\hline $\begin{array}{l}\text { Komiyama et al. } \\
\text { (2013) }\end{array}$ & BMS & brief group $\mathrm{CB}$ & healthy female controls & NRS, STAI, trait anxiety inventory score & $\begin{array}{l}\text { a brief group cognitive-behavioral } \\
\text { intervention decreased pain and anxiety } \\
\text { in BMS patients }\end{array}$ \\
\hline
\end{tabular}
visual analogue type scale

Table 2 Summary of characteristics of temporomandibular disorders

\begin{tabular}{|c|c|c|c|c|c|}
\hline Author (year) & $\begin{array}{l}\text { OFP symptoms } \\
\text { (TMD-related pain) }\end{array}$ & Intervention & Control & Outcome variables & Main findings \\
\hline $\begin{array}{l}\text { Dworkin et al. } \\
\text { (1994) }\end{array}$ & TMD & $\mathrm{CB}$ & UT & $\begin{array}{l}\text { characteristic pain, pain interference, } \\
\text { maximum assisted mandibular opening, } \\
\text { unassisted mandibular opening, SCL-90 } \\
\text { depression, SCL-90 somatization, } \\
\text { knowledge of TMD, post-treatment } \\
\text { satisfaction }\end{array}$ & $\begin{array}{l}\text { benefits of } \mathrm{CB} \text { intervention for temporo- } \\
\text { mandibular disorders }\end{array}$ \\
\hline Turk et al. (1996) & TMD & IA, SM, CT & IA, SM, Nondirective SC & $\begin{array}{l}\text { muscle palpation pain index, TMJ palpa- } \\
\text { tion pain index, unassisted mandibular } \\
\text { opening without pain, maximum unas- } \\
\text { sisted mandibular opening, McGill pain } \\
\text { questionnaire, BDI, PCS, CSQ, MPI, oral } \\
\text { parafunctional habits scale, self-reported } \\
\text { use of medication }\end{array}$ & $\begin{array}{l}\text { CT improved pain associated with muscle } \\
\text { palpation, self-reported pain severity, } \\
\text { depression, and use of medications }\end{array}$ \\
\hline $\begin{array}{l}\text { Dworkin et al. } \\
\text { (2002) }\end{array}$ & TMD & $\begin{array}{l}\text { CC - CBT-based program } \\
\text { for chronic pain adapted } \\
\text { for TMD (behavioral, } \\
\text { relaxation, cognitive } \\
\text { coping, explanatory model, } \\
\text { health care, personal plan, } \\
\text { maintenance and relapse } \\
\text { prevention) }\end{array}$ & UT & $\begin{array}{l}\text { characteristic pain intensity, pain-related } \\
\text { activity interference, vertical jaw range } \\
\text { of motion, number of extraoral muscle } \\
\text { palpations, SCL- } 90 \text { depression, SCL-90 } \\
\text { somatization }\end{array}$ & $\begin{array}{l}\text { six-session CBT intervention for } \\
\text { patients with heightened psychological } \\
\text { and psychosocial disability improved } \\
\text { pain-related variables }\end{array}$ \\
\hline $\begin{array}{l}\text { Gardea et al. } \\
(2001)\end{array}$ & Chronic TMD & $\begin{array}{l}\text { biofeedback, CBST, } \\
\text { combined biofeedback } \\
\text { and CBT }\end{array}$ & no treatment & $\begin{array}{l}\text { CPI, GCPS, and limitation in mandibular } \\
\text { functioning }\end{array}$ & $\begin{array}{l}\text { combined biofeedback and CBST treat- } \\
\text { ment produced the most comprehensive } \\
\text { improvements across subjective pain, } \\
\text { pain-related disability, and mandibular } \\
\text { functioning }\end{array}$ \\
\hline $\begin{array}{l}\text { Turner et al. } \\
(2005)\end{array}$ & Chronic TMD & a brief $\mathrm{CB}$ & $\begin{array}{l}\text { an education/attention } \\
\text { control condition, SCM }\end{array}$ & $\begin{array}{l}\text { activity interference, pain intensity, } \\
\text { jaw use limitations, negative mood, } \\
\text { pain-related beliefs, catastrophizing, and } \\
\text { coping }\end{array}$ & $\begin{array}{l}\text { a brief } \mathrm{CB} \text { treatment decreased } \\
\text { catastrophizing and improved activity } \\
\text { interference and jaw use limitations for } \\
\text { TMD patients }\end{array}$ \\
\hline $\begin{array}{l}\text { Turner et al. } \\
(2006)\end{array}$ & $\begin{array}{l}\text { TMD and facial } \\
\text { pain }\end{array}$ & $\mathrm{CBT}$ and education/attention & UT & $\begin{array}{l}\text { GCPS, CPI, jaw use limitations, MFIQ, } \\
\text { depression- BDI, SOPA, CSQ, PCS, } \\
\text { CPCI, treatment credibility }\end{array}$ & $\begin{array}{l}\text { a brief CBT intervention improved } 1 \text {-year } \\
\text { clinical outcomes of TMD clinic patients }\end{array}$ \\
\hline Litt et al. (2010) & TMD & $\begin{array}{l}\text { standard treatment plus CBT } \\
\text { condition }(\mathrm{STD}+\mathrm{CBT})\end{array}$ & $\begin{array}{l}\text { STD condition entailing } \\
\text { placement of a flat-plane } \\
\text { disoccluding splint, non- } \\
\text { steroidal anti-inflammatory } \\
\text { drugs }\end{array}$ & $\begin{array}{l}\text { MPI; characteristic pain intensity, CES-D } \\
(20 \text {-item) }\end{array}$ & $\begin{array}{l}\text { brief cognitive-behavioral treatment } \\
\text { reduced pain, life interference and depres- } \\
\text { sive symptoms in TMD sufferers }\end{array}$ \\
\hline
\end{tabular}

BDI, beck depression inventory; CB, cognitive behavioral; CBT, cognitive behavioral therapy; CBST, cognitive-behavioral skills training; CC, comprehensive care; CES-D: center for epidemiological studies depression scale; CT, cognitive therapy; CPI, characteristic pain intensity, CPCI: chronic pain coping inventory; CSQ, coping strategies questionnaire; GCPS, graded chronic pain scale; IA, intraoral appliance; MFIQ, mandibular function impairmen questionnaire; MPI, multidimensional pain inventory; OFP, orofacial pain; PCS, pain catastrophizing scale; SC, supportive counselling; SCL-90, symptom checklist-90; SCM, self-care management; SM, stress management with biofeedback, SOPA, survey of pain attitudes; STD, standard treatment; TMD, temporomandibular disorder; UT, usual treatment

[5]. In contrast, Femiano et al. reported that a combination of CBT and pharmacological therapy ( $\alpha$-lipoic acid $600 \mathrm{mg}$ per day for 2 months) led to a greater reduction in BMS symptoms than CBT alone and pharmacological therapy alone [6]. According to the International Association for the Study of Pain, simple daily activities such as eating, sucking on candy, chewing gum, having something sweet, sleeping, resting, and leisure may reduce BMS symptoms (International Association for the Study of Pain [IASP] (2016) orofacial pain fact sheets. burning mouth syndrome; https:// s3.amazonaws.com/rdcm-siasp/files/production/public/Content/ContentFolders/GlobalYearAgainstPain2/20132014OrofacialPain/FactSheets/ Burning_Mouth_Syndrome_2016.pdf) [7]. Therefore, dentists often recommend using strategies such as engaging in physical therapy by chewing sugarless gum at non-meal times and rolling sugarless candy on the tongue [2]. Existing evidence suggests that BMS pain management might begin with CBT, which could be combined as needed with a pharmaceutical intervention (Table 1).

Common treatments for TMD include stress management, cognitive restructuring, and relaxation [8]. Some systematic reviews report that short-term and long-term CBT was effective for patients with TMD, and the effectiveness for long-term pain symptoms was confirmed by a metaanalysis. CBT is generally performed by clinical psychologists; however, some patients with TMD have been effectively treated by dentists and dental hygienists trained in CBT [1].

To date, three studies have reported the effectiveness of CBT for patients with TMD-related pain [9-11]. Studies of the effectiveness of combined CBT classify TMD as (1) painless TMD without severe mental illness, (2) painful TMD without mental illness, and (3) painful TMD with severe mental illness [12] and include one report on CBT, intraoral 
Table 3 Summary of characteristics of myofascial pain syndrome

\begin{tabular}{|c|c|c|c|c|c|}
\hline Author (year) & OFP symptoms & CBT & Control & Outcome variables & Main findings \\
\hline $\begin{array}{l}\text { Komiyama et al. } \\
\text { (1999) }\end{array}$ & $\begin{array}{l}\text { MFP with limited } \\
\text { opening }\end{array}$ & $\begin{array}{l}\mathrm{CB}, \mathrm{CB} \text { with posture } \\
\text { correction }\end{array}$ & NI & $\begin{array}{l}\text { pain-free unassisted mouth opening, VAS, } \\
\text { disturbance in daily life }\end{array}$ & $\begin{array}{l}\mathrm{CB} \text { with posture correction alleviated } \\
\text { myofascial pain with limited mouth } \\
\text { opening }\end{array}$ \\
\hline $\begin{array}{l}\text { Bogart et al. } \\
(2007)\end{array}$ & masticatory MFP & CBT & before intervention & $\begin{array}{l}\text { pain intensity, duration, frequency } \\
\text { improvement }\end{array}$ & $\begin{array}{l}\text { efficacy of group CBT for treatment of } \\
\text { masticatory myofascial pain }\end{array}$ \\
\hline $\begin{array}{l}\text { Gatchel et al. } \\
(2006)\end{array}$ & TMD, MPF & Early CBT & NI & $\begin{array}{l}\text { pain, depression, ways of coping; } \\
\text { measures included a shortened version } \\
\text { of the RDC evaluation, BDI-II, ways of } \\
\text { coping, SCID-I and SCIDII, CPI }\end{array}$ & $\begin{array}{l}\text { early CBT reduced pain levels, improved } \\
\text { coping abilities, and reduced emotional } \\
\text { distress at } 1 \text { year }\end{array}$ \\
\hline $\begin{array}{l}\text { Ferrando et al. } \\
\text { (2012) }\end{array}$ & $\begin{array}{l}\text { TMD muscular } \\
\text { subgroup }\end{array}$ & CBT, hypnosis & control group & $\begin{array}{l}\text { No. of points painful on pressure, pain } \\
\text { frequency, self-medication frequency, } \\
\text { pain intensity, subjective pain index, pain } \\
\text { interference, pain severity, emotional } \\
\text { distress, BSI-18 anxiety, BSI-18 depres- } \\
\text { sion, BSI-18 somatization }\end{array}$ & $\begin{array}{l}\text { CBT including hypnosis improved } \\
\text { conservative standard treatment outcome } \\
\text { in TMD patients }\end{array}$ \\
\hline \multicolumn{6}{|c|}{$\begin{array}{l}\text { BDI, beck depression inventory; BSI, brief symptom inventory; CB, cognitive behavioral; CBT, cognitive behavioral therapy; CPI, characteristic pain intensity; MFP, myofascial pain; NI, non-intervention control; OFP, orofac } \\
\text { pain; RDC, research diagnostic criteria; SCID, structured clinical interview for DSM-IV; TMD, temporomandibular disorder; VAS, visual analogue scale }\end{array}$} \\
\hline Author (year) & OFP symptoms & CBT & Control & Outcome variables & Main findings \\
\hline $\begin{array}{l}\text { Wang et al. } \\
(2012)\end{array}$ & orthodontic pain & CBT intervention & $\begin{array}{l}\text { ibuprofen intervention, no } \\
\text { intervention }\end{array}$ & VAS, EPQ, T-AI, S-AI, SF-36 & $\begin{array}{l}\text { CBT effective in pain control during } \\
\text { initial stage of orthodontic treatment }\end{array}$ \\
\hline $\begin{array}{l}\text { Goldthorpe et al. } \\
\text { (2016) }\end{array}$ & COFP & $\mathrm{CBT}$ & $\begin{array}{l}\text { control group (treatment } \\
\text { as usual) }\end{array}$ & $\begin{array}{l}\text { assessed at baseline by PHQ-9 question- } \\
\text { naire }\end{array}$ & $\begin{array}{l}\text { CBT intervention acceptable for } \\
\text { unexplained COFP }\end{array}$ \\
\hline $\begin{array}{l}\text { Wang et al. } \\
(2015)\end{array}$ & orthodontic pain & $\mathrm{CBT}$ intervention & blank control group & $\begin{array}{l}\text { multichannel continuous electroencepha- } \\
\text { logram signals and VAS }\end{array}$ & $\begin{array}{l}\text { specific cerebral responses to CBT } \\
\text { instructions provide new insight in } \\
\text { exploring CBT for orthodontic pain } \\
\text { control }\end{array}$ \\
\hline $\begin{array}{l}\text { Huang et al. } \\
\text { (2016) }\end{array}$ & orthodontic pain & CBT & BWM or control & EEG signals, VAS & $\begin{array}{l}\text { brainwave music and CBT groups } \\
\text { reduced pain perception }\end{array}$ \\
\hline
\end{tabular}

BWM, brainwave music; CBT, cognitive behavioral therapy; COFP, chronic orofacial pain; EEG, electroencephalogram; EPQ, Eysenck personality questionnaire; OFP, orofacial pain; PHQ-9, patient health questionnaire-9; S-AI, state-anxiety inventory; SF-36, short form-36 health survey; T-AI, trait-anxiety inventory; VAS, visual analogue scale

appliances, stress management, and biofeedback; one on CBT, cognitive restructuring, and relaxation; one on $\mathrm{CBT}$ and biofeedback; and one on CBT and standard therapy (STD) [12-15]. Although CBT alone was effective in treating types (1) and (2), above, a comprehensive approach of stress management, cognitive restructuring, and relaxation, in conjunction with CBT, was effective for type (3). Turk et al. concluded that a combination of CBT, intraoral appliances, stress management, and biofeedback was effective against type (3) [16]. These results indicate that a comprehensive treatment approach that includes CBT should be considered for patients with TMD and psychosocial problems (Table 2).

Four studies have reported the effects of CBT on MFP [17-20]. Bogart et al. investigated the effects of CBT on MFP in 26 patients [19], 65\% of whom reported post-intervention improvement in pain intensity, duration, and frequency. Komiyama et al. compared combined CBT and postural correction with a non-CBT group and showed that participants with painful MFP had lower pain intensity (VAS) at maximum opening and an overall improvement in quality of daily life [17]. A study by Ferrando et al. found that CBT combined with hypnosis therapy improved pain frequency, intensity, and severity, anxiety, and somatization of mental pain [20]. Gatchel et al. established a CBT program and surveyed patients with MFP and TMD-related pain [18]. The CBT program included CBT, stress management, biofeedback, autonomous training, relaxation, and attention to habit behaviors that worsen or sustain symptoms (particularly avoidance and safety behaviors). Patients who underwent early CBT had significantly lower pain intensity and depression tendencies at 1 year after the intervention. Furthermore, participants in the nonintervention group were, as compared with those in the early intervention group, 12.5 times as likely to have a somatoform disorder, more than seven times as likely to have an anxiety disorder, and 2.7 times as likely to have an affective disorder at 1 year [18]. MFP-related pain may be induced and complicated by psychosocial factors and thus requires early intervention with $\mathrm{CBT}$ programs (Table 3).

Although Goldthorpe et al. reported that CBT is effective for patients with unexplained chronic orofacial pain, their study was excluded from a systematic review because it was not a case-control study [21]. As outlined above, although there are many practical studies of the use of CBT for TMD and MFP, few discuss unexplained disorders such as atypical toothache and atypical facial pain. Some studies investigated the effectiveness of hypnosis - from clinical and psychosocial perspectives - as non-CBT psychotherapy for atypical toothaches [22]. The results were mostly positive: hypnosis therapy appears to provide clinically appropriate pain relief for atypical toothache and improves sleep quality, with almost no adverse effects. However, because the evidence is limited, more studies are required in order to consider hypnosis therapy an effective option for clinical treatment. Unnecessary polypharmacy should be avoided in treating atypical toothache, and adjuvant therapies such as hypnosis are important and yield promising results [22].

Three recent case studies reported that CBT improved toothache during early orthodontic treatment [23-25]. Moreover, Wang et al. found that delta and theta brain waves were correlated with toothache intensity after dental treatment and that CBT reduced brain waves and pain caused by orthodontic treatment [23]. Furthermore, CBT combination therapy (brainwave music) improved toothache during orthodontic treatment. Thus, research has shown that, in pain-associated brain regions, CBT has some effect on brain wave patterns that occur during pain [25] (Table 4).

In sum, the present results indicate that CBT is useful for alleviating orofacial pain. A comprehensive approach combining CBT with intraoral appliances, stress management, biofeedback, CBT programs, cognitive restructuring, and relaxation may be useful for diseases such as chronic TMD. This review highlights the need for dentists to use CBT-related strategies as a first-line approach to manage orofacial pain.

\section{Acknowledgments}

This study was supported in part by a grant from the Japanese Dental Science Federation (JDSF-DSP1-2019-217-1).

\section{Conflict of interest}

The authors declare no conflict of interest. 


\section{References}

1. Aggarwal VR, Tickle M, Javidi H, Peters S (2010) Reviewing the evidence: can cognitive behavioral therapy improve outcomes for patients with chronic orofacial pain? J Orofac Pain 24, 163-171.

2. Bergdahl J, Anneroth G, Perris H (1995) Cognitive therapy in the treatment of patients with resistant burning mouth syndrome: a controlled study. J Oral Pathol Med 24, 213-215.

3. McMillan R, Forssell H, Buchanan JA, Glenny AM, Weldon JC, Zakrzewska JM (2016) Interventions for treating burning mouth syndrome. Cochrane Database Syst Rev 11, CD002779.

4. Matsuoka H, Himachi M, Furukawa H, Kobayashi S, Shoki H, Motoya R et al. (2010) Cognitive profile of patients with burning mouth syndrome in the Japanese population. Odontology 98, 160-164.

5. Komiyama O, Nishimura H, Makiyama Y, Iida T, Obara R, Shinoda M et al. (2013) Group cognitive-behavioral intervention for patients with burning mouth syndrome. J Oral Sci 55, $17-22$.

6. Femiano F, Gombos F, Scully C (2004) Burning mouth syndrome: open trial of psychotherapy alone, medication with alpha-lipoic acid (thioctic acid), and combination therapy. Med Oral 9, 8-13.

7. Grushka M (1987) Clinical features of burning mouth syndrome. Oral Surgery, Oral Surg Oral Med Oral Pathol 63, 30-36.

8. Matsuoka H, Chiba I, Sakano Y, Toyofuku A, Abiko Y (2017) Cognitive behavioral therapy for psychosomatic problems in dental settings. Biopsychosoc Med 11, 18.

9. Dworkin SF, Turner JA, Wilson L, Massoth D, Whitney C, Huggins KH et al. (1994) Brief group cognitive-behavioral intervention for temporomandibular disorders. Pain 59, 175187.

10. Turner JA, Mancl L, Aaron LA (2005) Brief cognitive-behavioral therapy for temporomandibular disorder pain: effects on daily electronic outcome and process measures. Pain 117, 377-387.

11. Turner JA, Mancl L, Aaron LA (2006) Short- and long-term efficacy of brief cognitivebehavioral therapy for patients with chronic temporomandibular disorder pain: a randomized, controlled trial. Pain 121, 181-194.

12. Dworkin SF, Turner JA, Mancl L, Wilson L, Massoth D, Huggins KH et al. (2002) A randomized clinical trial of a tailored comprehensive care treatment program for temporomandibular disorders. J Orofac Pain 16, 259-276.

13. Turk DC, Rudy TE, Kubinski JA, Zaki HS, Greco CM (1996) Dysfunctional patients with temporomandibular disorders: evaluating the efficacy of a tailored treatment protocol. J
Consult Clin Psychol 64, 139-146.

14. Gardea MA, Gatchel RJ, Mishra KD (2001) Long-term efficacy of biobehavioral treatment of temporomandibular disorders. J Behav Med 24, 341-359.

15. Litt MD, Shafer DM, Ibanez CR, Kreutzer DL, Tawfik-Yonkers Z (2009) Momentary pain and coping in temporomandibular disorder pain: exploring mechanisms of cognitive behavioral treatment for chronic pain. Pain 145, 160-168.

16. Türp JC, Jokstad A, Motschall E, Schindler HJ, Windecker-Gétaz I, Ettlin DA (2007) Is there a superiority of multimodal as opposed to simple therapy in patients with temporomandibular disorders? A qualitative systematic review of the literature. Clin Oral Implants Res 18, 138-150.

17. Komiyama O, Kawara M, Arai M, Asano T, Kobayashi K (1999) Posture correction as part of behavioural therapy in treatment of myofascial pain with limited opening. J Oral Rehabil $26,428-435$.

18. Gatchel RJ, Stowell AW, Wildenstein L, Riggs R, Ellis E 3rd (2006) Efficacy of an early intervention for patients with acute temporomandibular disorder-related pain: a one-year outcome study. J Am Dent Assoc 137, 339-347.

19. Bogart RK, McDaniel RJ, Dunn WJ, Hunter C, Peterson AL, Wright EF (2007) Efficacy of group cognitive behavior therapy for the treatment of masticatory myofascial pain. Mil Med 172, 169-174.

20. Ferrando M, Galdón MJ, Durá E, Andreu Y, Jiménez Y, Poveda R (2012) Enhancing the efficacy of treatment for temporomandibular patients with muscular diagnosis through cognitive-behavioral intervention, including hypnosis: a randomized study. Oral Surg Oral Med Oral Pathol Oral Radiol 113, 81-89.

21. Goldthorpe J, Peters S, Lovell K, McGowan L, Aggarwal V (2016) 'I just wanted someone to tell me it wasn't all in my mind and do something for me': qualitative exploration of acceptability of a CBT based intervention to manage chronic orofacial pain. Br Dent J 220 , 459-463.

22. Abrahamsen R, Baad-Hansen L, Svensson P (2008) Hypnosis in the management of persistent idiopathic orofacial pain--clinical and psychosocial findings. Pain 136, 44-52.

23. Wang J, Jian F, Chen J, Ye NS, Huang YH, Wang S et al. (2012) Cognitive behavioral therapy for orthodontic pain control: a randomized trial. J Dent Res 91, 580-585.

24. Wang J, Wu D, Shen Y, Zhang Y, Xu Y, Tang X et al. (2015) Cognitive behavioral therapy eases orthodontic pain: EEG states and functional connectivity analysis. Oral Dis 21, 572582.

25. Huang R, Wang J, Wu D, Long H, Yang X, Liuet H et al. (2016) The effects of customised brainwave music on orofacial pain induced by orthodontic tooth movement. Oral Dis 22 , $766-774$ 